Querido Filip Timofeievitch: leer esta carta quizás le haga comprender todo lo que tuve que soportar antes de escribirle.

Andrei Tarkovski al presidente de Goskino

La gota que hizo rebalsar el vaso fue, siniestro recuerdo, el Festival de Cannes. Grande fue mi sorpresa cuando me enteré que el Goskino no solamente no se oponía a que Nostalghia fuera seleccionada para ser presentada en Cannes, sino que además alentaba esa elección. Después de pensarlo me dije: ¿por qué no asociar una eventual victoria en Cannes con una victoria en el marco general del cine soviético? Desde cierto punto de vista me parecía tan legítimo como lógico. En cuanto a usted, sabiendo perfectamente que el film iba a ser seleccionado para el festival, mandó como delegado a B. (del que todo el mundo conoce su actitud hacia mí) para que observara de cerca el fracaso de Nostalghia. Otro hecho conocido: el Goskino insistió expresamente para que B. fuera el miembro soviético del jurado.

Esta mascarada resulta todavía más detestable ya que $\mathrm{MM}, \mathrm{K}, \mathrm{S}$ y N , trataron, con demasiada insistencia, de convencerme de que usted era el que le había sugerido a $B$ que tuviera una actitud leal hacia mí en Cannes. Pregunta: ¿Por qué había que mandar a B - con su conocido "amor» por Tarkovski- y no a otro, insistiendo en ese candidato, si el presidente del Goskino quería que la victoria fuera para un film realizado por un director soviético? Era claro como el agua... Todo esto no es más que la continuación lógica de las persecuciones 


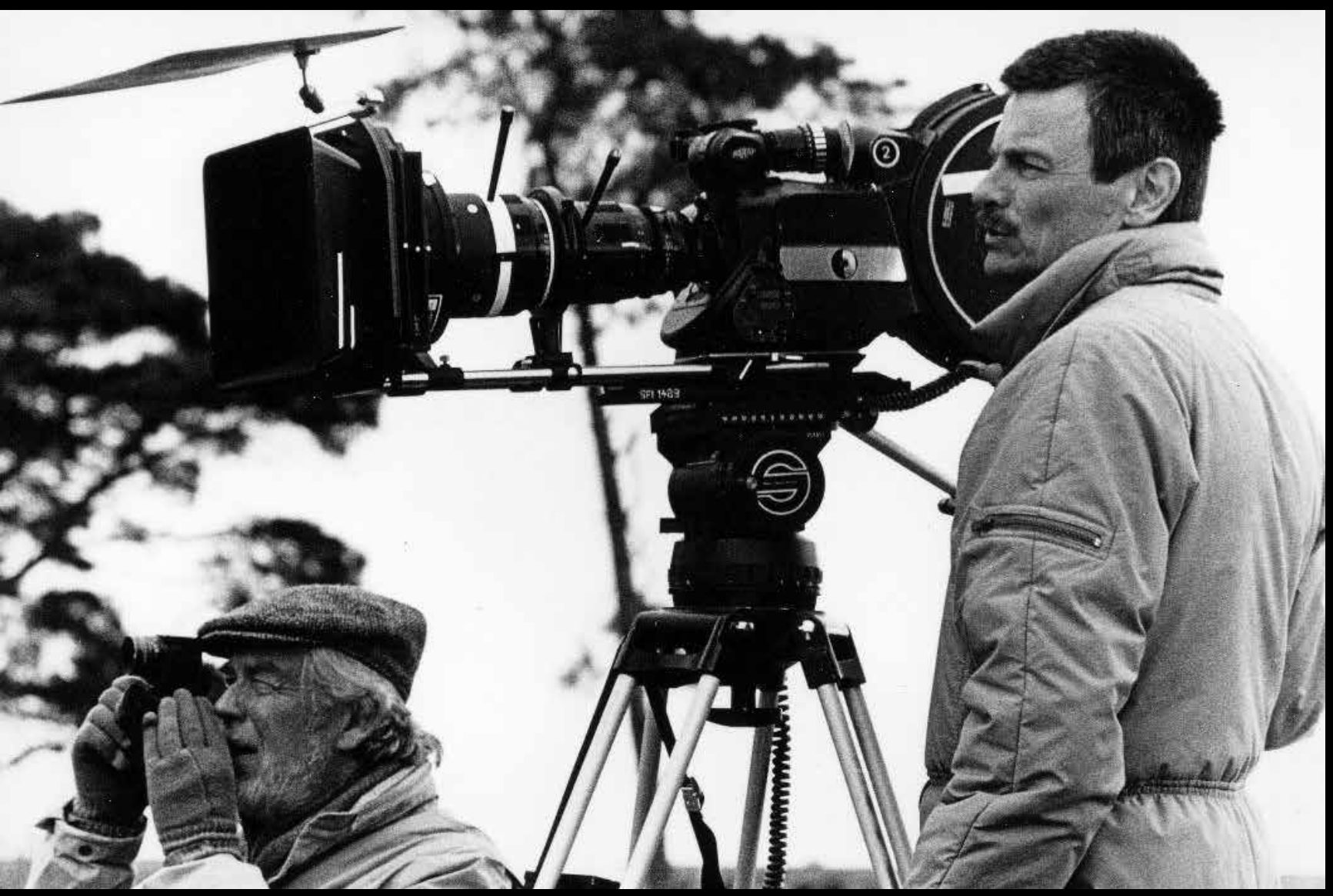


sin precedentes de las cuales he sido objeto desde hace más de veinte años. De hecho ha habido precedentes: recuerde usted el destino de S.M. Eisenstein. ¿Qué es lo que hice yo durante estos veinte años?

\section{LA INFANCIA DE IVÁN}

El film fue acusado de pacifista, a pesar de su gran éxito. $\mathrm{Ni}$ aún la buena opinión que del film tenía el difunto $S$. ayudó a su distribución. En Moscú el film fue proyectado en funciones para niños (¿lo hicieron a propósito para burlarse de la idea del film?). Dicho de otra manera, todo fue hecho para contrarrestar el éxito del film en Occidente, con una inexistente distribución en el territorio nacional.

\section{ANDREI ROUBLEV}

Este caso es sin comentarios. Apreciación del film en una proyección del Goskino a la cual asistieron casi todos los realizadores que trabajan en Moscú: «Hace mucho que no se veía una obra tan grandiosa y destacable». La opinión fue unánime. Yo no esperaba, debo reconocer, semejante acogida por parte de mis celosos colegas. Consecuencia: congelamiento del film durante seis años, y yo, durante todo este tiempo, sin trabajo. Mis proyectos fueron rechazados $y$ me quedé sin ningún ingreso.(Hoy, en la opinión de la crítica internacional, Andrei Roublev forma parte de las diez mejores películas de todos los tiempos).

\section{SOLARIS}

El Goskino no la quería. Conservé la copia de la lista de las observaciones que debía respetar. (Muy buena lectura) iEran cuarenta y ocho! y todas ellas serías, al más alto nivel. Pero sucedió algo milagroso y la película fue aceptada, esta vez, sin observaciones. Clasificada además en la categoría más alta —mis otros films fueron clasificados en la segunda categoría, para indicar mi valor tanto como el lugar que me correspondía. Este es mi único film -el menos logrado según mi parecer- que se benefició de una distribución correcta en la URSS.

\section{EL ESPEJO}

Opinión del presidente de la Goskino después de la proyección: «No entendí nada». El vértice de la pirámide ostenta la verdad, se podría decir. Eso significaba que si usted mismo no había entendido nada, nadie en el mundo sería capaz de hacerlo. Consecuencia: clasificación en la segunda categoría, una cantidad despreciable de copias - para que el autor no tenga nada que comer y una vez más para que conozca su lugar y sepa lo que vale- Ninguna repercusión en la prensa, condenada al silencio.

\section{STALKER}

La misma historia de El espejo. Silencio en la prensa. Dos o tres artículos injuriosos escritos por encargo. Otra vez segunda categoría, tiraje de copias inferior al mínimo legal otorgado a la segunda categoría -mientras que en Tachent, a pedido de los espectadores que quieren verlo, se proyectan una copia en blanco y negro, en lugar de las copias tiraje-. Y la mayoría de los distribuidores de las ciudades alejadas de la URSS hablan de la imposibilidad de proyectar los films de Tarkovki dada la existencia de una 
circular especial que estipula una limitación de las proyecciones de mis películas. Por suerte también he guardado una copia de esta circular. Y de nuevo, silencio, número limitado de copias, multas en dinero -que según las leyes soviéticas ya no existen- etc. $Y$ ahora esta historia con Nostalghia.

Los mismos $\mathrm{K}, \mathrm{S}, \mathrm{N}$ y $\mathrm{M}$ tratan de convencerme de que $\mathrm{E}$ quiere seleccionar el film para el Festival de Moscú. iBasta de mentiras, basta!

Paremos con estas mentiras hipócritas que no los honran ni como seres humanos ni como dirigentes del cine soviético.

¿Cuáles fueron los ecos que llegaron al país sobre un film realizado por un director soviético en el extranjero? Puede usted apreciar la insinuación publicada en $\mathrm{La}$ cultura soviética del 24 de mayo. Aún si usted conoce este tipo de artículos, qué manera de defender el honor de un realizador soviético que trabaja en el extranjero y que hace lo mejor que puede para hacer un film realmente necesario y patriótico. iGracias! Nada nuevo, estoy en terreno conocido.

¿Cómo explicar estas persecuciones desde hace tantos años? Nunca pude entender las razones...

Entonces, en veintidós años de trabajo en la URSS dirigí cinco films, o sea un film cada cuatro años y medio. Si la realización de un film necesita más o menos un año, más el tiempo que lleva la escritura de un guión, entonces, en estos veintidós años estuve dieciséis años sin trabajo. Sin embargo, el Goskino lucra con el éxito de mis films en el extranjero, mientras que yo, la mayor parte del tiempo, no sé cómo hacer para mantener a mi familia.

A partir de su nominación a la presidencia del Goskino ninguno de mis films fue seleccionado para ningún festival internacional.
Desde que usted está en ese puesto nunca aceptó ninguno de mis proyectos motu proprio. Con El espejo lo había logrado, pero solo después de haberme dirigido por escrito al Presidente del XXIV Congreso del PCUS. Con Stalker también, pero solo después de mi carta al Presidente del XXVI Congreso. No puedo seguir molestando a nuestros dirigentes del partido y esperar cada vez el nuevo congreso para poder ejercer mi profesión.

El Goskino recibe a menudo cartas para mí, cartas de invitación a festivales internacionales, a coloquios, a los estrenos de mis películas, ni siquiera se me informa de ello. Las esconden sistemáticamente, me entero de la existencia de todas esas invitaciones por azar, por medio de cineastas extranjeros.

A comienzos del 82, me habían propuesto dirigir un Taller de realizadores y guionistas, en el marco de los cursos de perfeccionamiento para los realizadores. Estuve trabajando larga y minuciosamente en ese sentido y seleccioné cinco personas de las candidaturas presentadas. Ninguna de ellas fue aceptada, lo cual significa que me quedé sin alumnos y sin taller. Usted no lo puede ignorar, había solicitado su ayuda para conservar este curso y jamás recibí una respuesta. Pregunto: ¿Por qué haberme propuesto hipócritamente crear mi taller sabiendo de antemano que no lo iba a tener? ¿Para mentirme? ¿Por qué? ¿Para que de vez en cuando piense que el presidente del Goskino me «aprecia», como tratan de de convencerme sus adjuntos y colaboradores? ¿Por qué pretende que piense eso? La respuesta es clara, porque su hostilidad no tiene ninguna razón de ser, porque no me merezco, objetivamente, semejante actitud, porque si hubiera una razón ya me hubiera muerto de hambre hace mucho tiempo. 
Le di al arte cinematográfico soviético todas mis fuerzas, todo mi savoir faire, todas mis capacidades. En la medida de mis posibilidades siempre contribuí a su gloria y a su repercusión en el mundo. En mis viajes de trabajo al exterior siempre defendí los intereses del cine soviético. nadie puede afirmar lo contrario. Usted no ignora que mi imagen pública y mi comportamiento durante esos viajes son irreprochables. No puedo ni siquiera imaginarme una actitud diferente hacia mi actividad en el extranjero porque se trata aquí de conciencia y de convicciones. Estoy dispuesto a servir conscientemente pero nunca a buscar el favor de alguien. Soy un artista y un ciudadano soviético, no un sirviente.

Durante la realización de Nostalghia, la parte soviética del equipo de filmación hizo todo para que el film reflejase mis opiniones más profundas: hicimos un film «patriótico», que dice que la nostalgia es una enfermedad mortal para el hombre ruso, alejado de su patria, aun provisoriamente. Es evidente y aquí en Occidente muchos críticos lo han remarcado. A pesar de lo que puedan decir mis «benefactores». Hasta nos reímos aquí: «es una película que tendrían que mostrar allá, en el mostrador de los pasaportes, a los que tienen la intención de irse al extranjero". Debo subrayar además que los italianos estuvieron encantados por la mirada que tiene un realizador soviético sobre Italia. Efectivamente a través del film Italia no aparece para nada como una institución turística sino como un lugar de sufrimiento y tormento sociales. ¿Pero qué es lo que hay que explicar? ¿Explicar lo inexplicable?

En veinte años de carrera en mi país nunca recibí ninguna distinción, ningún premio, nunca participé en ningún festival soviético. ¿No indica esto su real actitud hacia mi larga, y le puedo asegurar, difícil acti- vidad? Cuando cumplí 50 años, ningún miembro de los círculos cinematográficos oficiales se acordó siquiera de mi existencia. Cuando estuve hospitalizado por un infarto, nadie vino a visitarme. Una sola vez, una persona extraña vino, y aun ahí, era para saber si estaba realmente enfermo. Como si tuviera la peste. Mientras me restablecía pedí a la Unión de Cineastas una prescripción gratis para una cura en un sanatorio especializado en enfermedades cardiovasculares. Me la rechazaron. Sin comentarios. ¿Puede usted negar esto? No, porque es la verdad, y las pruebas son numerosas, mucho más que en esta carta.

Filip Timofeievitch: Estoy cansado. Cansado de persecución, de su odio, de su maldad, de la miseria, y en fin, de la ausencia sistemática de trabajo a la cual usted me ha condenado. La historia de Cannes fue la gota que rebalsó el vaso. Simplemente me remató. Por fin puede usted felicitarse.

Hoy recibo muchas propuestas profesionales aquí, en Roma, tanto en cine como en teatro y en las escuelas de cine. Me gustaría trabajar cierto tiempo aquí, eligiendo, por supuesto, las propuestas aceptables del punto de vista de las ideas. Puedo mencionar la ópera de Moussorgski «Boris Godounod», en Londres, y el film «Hamlet» (de Shakespeare), que es un viejo sueño mío. Le ruego que considere esta carta como un documento oficial (guardaré una copia) en la cual el realizador de los Estudios Mosfilm Andrei Tarkovski, después de haber soportado demasiadas persecuciones de parte del Goskino de la URSS, se dirige al presidente E. para pedirle que le sea concedido a él, a su esposa L.P. Tarkovskaia, a su suegra A.S. Egorkina y a su hijo Andrei Tarkovski (doce años), pasaportes soviéticos autorizando una estadía temporaria de tres años en Italia, para ejercer allí su profesión. 
No podemos dudar, Filip T., que a pesar del perjuicio moral que me causó durante todos estos años, y que me inflijo yo mismo por la presente (no es tan fácil trabajar en Occidente), permanezco fiel a mi patria como hombre y como artista soviético, que no solamente no tiene intención de perjudicarlo sino, por el contrario, de «elevar lo más posible la importancia del cine soviético en la escena internacional»». Usted siempre me presionó para que hoy me vea obligado a tomar esta decisión.
¿Quizá usted quería de esta manera desembarazarse por cierto tiempo de un colaborador molesto? No le será tan fácil. No le será simple a usted desembarazarse de mí. Déjeme solamente respirar un poco.

Espero su respuesta en un futuro próximo, y si esta no llegara, tendré que dirigirme entonces a la redacción del diario Pravda, con una carta abierta en la cual me vería obligado a explicitar las razones que me han llevado a pedir la autorización para trabajar temporariamente en el extranjero. 